\title{
Unintentional fatal injuries arising from unpaid work at home
}

\author{
T R Driscoll, R J Mitchell, A L Hendrie, S H Healey, J A Mandryk, B P Hull
}

Injury Prevention 2003;9:15-19 See end of article for
authors' affiliations

Correspondence to: Dr Timothy Driscoll, Centre for Occupational and Environmental Health, School of Public Health and Community Medicine, University of Sydney. C/49 Taleeban Road, Riverview NSW 2066, Australia;

elmatom@optushome.com.au

\begin{abstract}
Objective: Unpaid work in and around the home is a common and potentially high risk activity, yet there is limited information about the circumstances surrounding resulting injuries. This study aimed to describe circumstances surrounding fatal injuries resulting from home duties activities, in order to identify and prioritise areas for prevention.

Design and setting: Coroners' reports on all unintentional deaths in Australia from 1989-92 inclusive were inspected to identify deaths of interest. Rates were calculated using population data and incorporating measures of time engaged in particular home duties activities.

Results: There were 296 home duties deaths over the four year period. Most (83\%) deaths were of males, and males had 10 times the risk of fatal injury compared with females. The most common activities resulting in fatal injuries were home repairs, gardening, and car care. The highest risk activities (deaths per million persons per year per hour of activity) were home repairs (49), car care (20), home improvements (18), and gardening (16). Being hit by inadequately braced vehicles during car maintenance, falls from inadequately braced ladders, contact with fire and flames while cooking, and contact with electricity during maintenance were the most common injury scenarios.

Conclusions: Fatal injury of persons engaged in unpaid domestic work activities is a significant cause of death. Use of activity specific denominator data allows appropriate assessment of the degree of risk associated with each activity. The recurrence of similar circumstances surrounding many independent fatal incidents indicates areas where preventative interventions might be usefully targeted.
\end{abstract}

npaid work in and around the home is increasingly seen as being as important to society as paid employment. There are similarities between the tasks that are performed regardless of any remuneration involved. Domestic food preparation and clean-up, housework, gardening, building and car maintenance, and home improvements all have parallels in the employed sector, and indeed many household tasks are being more commonly performed under a loose contractual arrangement by persons retained on a casual basis.

These activities also potentially involve significant risk. However, although injuries commonly occur at home, there is very limited information available on the circumstances surrounding fatal or non-fatal injury from home duties activities in domestic settings. Most of the available information describes non-fatal injuries, does not separately identify injuries arising from home duties activities, and/or focuses on elderly persons injured as a result of falls..$^{2-8}$ When rates of injury have been determined, they have nearly always been based on general population data, rather than time spent in the home or, ideally, time spent undertaking activities. Therefore, appropriate risk data have not been available.

This paper considers fatal incidents arising from home duties, including determining activity based rates and describing common injury scenarios, with the aim of identifying and prioritising activities designed to prevent these occurrences.

\section{METHOD}

Fatal incidents involving unpaid workers in domestic situations ("home duties" deaths) were identified and examined in detail as part of a study of all work related fatalities in Australia. The method is described in detail elsewhere, and is summarised here. ${ }^{9}$

The overall study considered non-suicide work related traumatic deaths that occurred over a four year period, 1989-92, and was based on information collected from coroners' files in each of the Australian states and territories. Virtually all external cause deaths in Australia are investigated by a coroner. However, since the coroners' offices do not have consistent coding systems to identify work related deaths, it was necessary to inspect all potentially relevant coroners' files in order to determine if the circumstances of the fatal incident met the study definitions of work relatedness.

The coroners' files relating to these deaths were read and deaths classified as cases (that is, work related), non-cases (that is, not work related), or indeterminate. File information for the deaths found to be work related was photocopied and the photocopied information later coded into a computerised database and analysed. Files were found for $99.7 \%$ of the original 22957 deaths of interest. Of the 22957 deaths, 3630 (15.8\%) were confirmed as cases, 17805 (77.6\%) were excluded as non-work related, and $1522(6.6 \%)$ were excluded as indeterminate. Most of the indeterminate cases involved persons travelling in vehicles for whom the purpose of the journey was unknown. They were therefore likely to be outside the scope of the study definitions for home duties, which excluded travel (described below).

A broad definition of work relatedness was used in this study, and cases were divided into eight categories, one of which was "home duties". It is these cases that are the focus of the analysis presented here. The group of interest comprised persons who were performing duties at home (or in someone else's home) in an unpaid capacity and that might conceivably be performed by someone in a paid capacity. There was some unavoidable arbitrariness to the inclusions and exclusions, but the working definition used was based on that used in a recent survey by the Australian Bureau of Statistics (ABS), although it was not as broad as the ABS definition. ${ }^{10}$ Unpaid home duties included under this definition were all food and drink preparation and clean-up; laundry, ironing and 
Table 1 Fatally injured home duties persons by sex and age, and overall, Australia, 1989-92 inclusive

\begin{tabular}{|c|c|c|c|c|c|}
\hline Age & No $(\%)$ & Rate* & $\begin{array}{l}95 \% \text { confidence } \\
\text { interval }\end{array}$ & Rate† & $\begin{array}{l}95 \% \text { confidence } \\
\text { interval }\end{array}$ \\
\hline \multicolumn{6}{|l|}{ Males } \\
\hline $15-24$ & $19(7.7)$ & 3.38 & 2.03 to 5.29 & 55.0 & 33.0 to 85.9 \\
\hline $25-34$ & 35 (14.2) & 6.20 & 4.32 to 8.62 & 44.8 & 31.2 to 62.3 \\
\hline $35-44$ & $29(11.7)$ & 5.56 & 3.72 to 7.98 & 34.4 & 23.0 to 49.4 \\
\hline $45-54$ & $24(9.7)$ & 6.35 & 4.07 to 9.44 & 32.7 & 21.0 to 48.6 \\
\hline $55-64$ & 42 (17.0) & 14.29 & 10.31 to 19.32 & 57.4 & 41.4 to 77.6 \\
\hline $65-74$ & $50(20.2)$ & 23.11 & 17.15 to 30.46 & 69.1 & 51.2 to 91.0 \\
\hline $75+$ & 48 (19.4) & 42.48 & 31.33 to 56.29 & 131.5 & 97.0 to 174.2 \\
\hline All ages & 247 (100.0) & 9.32 & 8.16 to 10.49 & 45.2 & 39.5 to 50.8 \\
\hline \multicolumn{6}{|l|}{ Females } \\
\hline $15-24$ & $2(4.1)$ & - & & - & \\
\hline $25-34$ & $2(4.1)$ & - & & - & \\
\hline $35-44$ & $2(4.1)$ & - & & - & \\
\hline $45-54$ & $3(6.1)$ & 0.83 & 0.17 to 2.44 & 1.9 & 0.4 to 5.7 \\
\hline $55-64$ & $9(18.4)$ & 3.08 & 1.40 to 5.86 & 6.6 & 3.0 to 12.6 \\
\hline $65-74$ & $9(18.4)$ & 3.59 & 1.64 to 6.82 & 7.3 & 3.3 to 13.9 \\
\hline $75+$ & $22(44.9)$ & 11.61 & 7.28 to 17.57 & 27.8 & 17.5 to 42.1 \\
\hline All ages & 49 (100.0) & 1.81 & 1.34 to 2.39 & 4.3 & 3.2 to 5.7 \\
\hline \multicolumn{6}{|l|}{ Persons } \\
\hline $15-24$ & $21(7.1)$ & 1.90 & 1.18 to 2.91 & 19.4 & 12.0 to 29.6 \\
\hline $25-34$ & 37 (12.5) & 3.29 & 2.32 to 4.53 & 14.8 & 10.4 to 20.3 \\
\hline $35-44$ & $31(10.5)$ & 2.99 & 2.04 to 4.25 & 10.8 & 7.4 to 15.4 \\
\hline $45-54$ & $27(9.1)$ & 3.66 & 2.41 to 5.32 & 11.8 & 7.8 to 17.2 \\
\hline $55-64$ & $51(17.2)$ & 8.70 & 6.48 to 11.45 & 24.4 & 18.2 to 32.1 \\
\hline $65-74$ & 59 (19.9) & 12.63 & 9.61 to 16.29 & 30.2 & 23.0 to 39.0 \\
\hline $75+$ & 70 (23.7) & 23.14 & 18.05 to 29.22 & 60.9 & 47.5 to 76.9 \\
\hline All ages & 296 (100.0) & 5.53 & 4.90 to 6.15 & 17.7 & 15.7 to 19.7 \\
\hline
\end{tabular}

clothes care; other housework (such as cleaning, dusting, polishing, vacuuming, etc); gardening and grounds care (gardening, lawn care, pool care, pet/animal care); home maintenance (including home improvement and car care); some aspects of the care or minding of children or others; and other domestic activities (such as household paperwork, bills, etc). Unpaid activities that involved travelling (such as driving to a shop for food; catching a train to buy clothes; or flying to take children for a holiday) were excluded, as were passive activities such as sitting in a chair while babysitting, and all leisure activities. Only persons 15 years and over were included.

Workers fatally injured in connection with their work were specifically excluded from the home duties group. Work related deaths of workers (as opposed to home duties cases) encompassed all people working for pay, profit or payment-inkind, including unpaid work in a family business or on a farm. Also excluded were fatal incidents during formal volunteer work and while travelling on public roads. Home duties cases comprised $8.2 \%$ of all cases in the study.

Rates were calculated using two approaches. One approach used the Australian population data published annually by the ABS. ${ }^{11}$ These rates are expressed as deaths per million persons per year. The second approach used the population data, but also took account of information on the amount of time spent undertaking various activities at home. This allowed rates to be determined incorporating information on exposure to various home duties tasks. This exposure information was obtained from two ABS time use survey publications that presented time use survey data collected in 1992.. ${ }^{12}$ The survey collected information on the amount of time spent on various activities during a week. By combining age and sex specific information from the two surveys, denominators for males, females and persons, overall and by age, were produced. Data were collected over 12 months via two day diaries from a random sample of persons throughout Australia. The final denominators were determined by multiplying the population by the number of hours spent per week in a given activity and by 52 (the number of weeks in a year), with the resulting rates expressed as deaths per million persons per year per hour of activity. Activity specific denominator information was only available for broad categories. For example, time spent on home maintenance activity was known, but estimates of time spent performing specific home maintenance tasks such as home repairs and car care were not available. Exposure based rates for specific categories were calculated using the denominators for the whole relevant broad category, and therefore are likely to underestimate the true rate for specific categories. Only rates based on three or more deaths are reported. Confidence intervals are based on the Poisson distribution.

\section{RESULTS}

There were 296 persons aged 15 years and over who died during the four year period 1989-92 and whose circumstance of injury met the definition of home duties death (another two persons less than 15 years were excluded). Seventy eight percent of persons lived in the place where the incident occurred. The overall rate of death on a population basis was 5.5 deaths per 1000000 persons per year. Taking into account time spent undertaking home duties, this was a rate of 17.7 deaths per 1000000 persons per year per hour of home duties activity.

The vast majority of the home duties deaths were of males $(83 \%)$. The overall rate of death for males was about five times higher than females on a population basis, and 10 times higher when time spent undertaking home duties activity was taken into account. All ages from 15 years and upwards had a considerable number of deaths, although the proportion of total deaths increased in the older age groups, and rates increased considerably in the older age groups. Most women (82\%) were 55 years or older, and $45 \%$ were 75 years or older. 
Table 2 Fatally injured home duties persons by main activities-all persons, Australia, 1989-92 inclusive

\begin{tabular}{|c|c|c|c|c|c|}
\hline Activity & No (\%) & Rate* $^{*}$ & $\begin{array}{l}95 \% \text { confidence } \\
\text { interval }\end{array}$ & Rate† & $\begin{array}{l}95 \% \text { confidence } \\
\text { interval }\end{array}$ \\
\hline All housework & $46(15.5)$ & 0.86 & 0.63 to 1.15 & 3.9 & 2.9 to 5.3 \\
\hline Food and drink preparation & $29(9.8)$ & 0.54 & 0.36 to 0.78 & 2.5 & 1.7 to 3.6 \\
\hline Laundry & $7(2.4)$ & 0.13 & 0.05 to 0.27 & 0.6 & 0.2 to 1.2 \\
\hline Other & $10(3.4)$ & 0.19 & 0.09 to 0.34 & 0.9 & 0.4 to 1.6 \\
\hline All grounds/animal care & $94(31.8)$ & 1.75 & 1.42 to 2.15 & 27.0 & 21.8 to 33.0 \\
\hline Gardening & $56(18.9)$ & 1.05 & 0.79 to 1.36 & 16.1 & 12.1 to 20.9 \\
\hline Cleaning grounds & $18(6.1)$ & 0.34 & 0.20 to 0.53 & 5.2 & 3.1 to 8.1 \\
\hline Pets & $10(3.4)$ & 0.19 & 0.09 to 0.34 & 2.9 & 1.4 to 5.3 \\
\hline Other & $10(3.4)$ & 0.19 & 0.09 to 0.34 & 2.9 & 1.4 to 5.3 \\
\hline All home maintenance & $141(47.6)$ & 2.63 & 2.20 to 3.07 & 90.2 & 75.3 to 105.1 \\
\hline Home repairs & $77(26.0)$ & 1.44 & 1.13 to 1.80 & 49.3 & 38.9 to 61.6 \\
\hline Home improvements & $28(9.5)$ & 0.52 & 0.35 to 0.76 & 17.9 & 11.9 to 25.9 \\
\hline Car care & $31(10.5)$ & 0.58 & 0.39 to 0.82 & 19.8 & 13.5 to 28.2 \\
\hline Other & $5(1.6)$ & 0.09 & 0.03 to 0.22 & 3.2 & 1.0 to 7.5 \\
\hline Other & $13(4.4)$ & 0.24 & 0.13 to 0.41 & - & \\
\hline Not known & $2(0.7)$ & - & & - & \\
\hline Total & 296 (100.0) & 5.53 & 4.90 to 6.15 & 17.7 & 15.7 to 19.7 \\
\hline
\end{tabular}

Table 3 Fatally injured home duties persons by main activities-males and females separately, Australia, 1989-92 inclusive

\begin{tabular}{|c|c|c|c|c|c|}
\hline Sex and activity & No (\%) & Rate* & $\begin{array}{l}95 \% \text { confidence } \\
\text { interval }\end{array}$ & Rate† & $\begin{array}{l}95 \% \text { confidence } \\
\text { interval }\end{array}$ \\
\hline \multicolumn{6}{|l|}{ Males } \\
\hline Housework & $23(9.3)$ & 0.87 & 0.55 to 1.30 & 9.9 & 6.3 to 14.9 \\
\hline Grounds and animal care & $77(31.2)$ & 2.91 & 2.30 to 3.63 & 40.5 & 32.0 to 50.6 \\
\hline Home maintenance & $138(55.9)$ & 5.21 & 4.34 to 6.08 & 110.6 & 92.1 to 129.0 \\
\hline Other and unknown & $9(3.6)$ & 0.34 & 0.15 to 0.65 & - & \\
\hline Total & 247 (100.0) & 9.32 & 8.16 to 10.49 & 45.2 & 39.5 to 50.8 \\
\hline \multicolumn{6}{|l|}{ Females } \\
\hline Housework & $23(46.9)$ & 0.85 & 0.55 to 1.30 & 2.4 & 1.5 to 3.6 \\
\hline Grounds and animal care & $17(34.7)$ & 0.63 & 0.37 to 1.03 & 11.2 & 6.5 to 17.9 \\
\hline Home maintenance & $3(6.1)$ & 0.11 & 0.02 to 0.33 & 9.9 & 2.0 to 29.0 \\
\hline Other and unknown & 6 (12.2) & 0.22 & 0.08 to 0.49 & - & \\
\hline Total & 49 (100.0) & 1.81 & 1.37 to 2.45 & 4.3 & 3.2 to 5.7 \\
\hline
\end{tabular}

This contrasted with men, of whom $56 \%$ were 55 years or older and only $19 \%$ were 75 years or older (table 1).

The most common broad activity at the time of the fatal incidents was home maintenance, followed by grounds and animal care and housework. The population rates reflected these proportions, since they were all based on the same denominator, with the home maintenance: grounds care: housework ratio being 3:2:1. However, the exposure based rates had much greater differences between activities, with ratios of 22:6:1. At a more specific level, the most common activities at the time of the fatal incidents, in order of decreasing percentage, were home repairs, gardening, car care, food and drink preparation, home improvements, and cleaning grounds. Food and drink preparation was relatively much less important when exposure was taken into account, with the highest time use rates being for home repairs, car care, home improvements, and gardening (table 2).

For men, maintenance was the predominant activity at the time of the fatal incident, along with grounds and animal care. For women, housework was the most commonly involved activity, followed by grounds and animal care. Proportionately few men were involved in housework deaths, and very few women were involved in home maintenance deaths. Men had far higher rates of death than women for most activities, whether only on the basis of population, or also taking into account time spent performing activities. Only for housework were the male and female rates similar, and even for this activity the males rates were four times higher when time spent on housework was taken into account (table 3).

Home maintenance was the predominant involved activity for nearly all age groups below 75 years. Above 75 years, housework became increasingly dominant, while grounds care and maintenance became less dominant.

The most common mechanisms of the fatal incidents were falls from a height (28\%), contact with electricity ( $19 \%)$, being hit by falling objects $(12 \%)$, and contact with heat $(12 \%)$. In younger age groups, contact with electricity was by far the largest single mechanism ( $45 \%$ of deaths in the age group), whereas falls (44\%) and contact with hot objects (this category covered being burnt in fires) $(27 \%)$ were the most common mechanisms in the older age groups. However, the 
Table 4 Home duties fatal incidents-mechanism by age of injured person, Australia, 1989-92 inclusive; values are percent

\begin{tabular}{|c|c|c|c|c|c|}
\hline \multirow[b]{2}{*}{ Mechanism } & \multicolumn{4}{|c|}{ Age (years) } & \multirow[b]{2}{*}{$\begin{array}{l}\text { Total } \\
(n=296)\end{array}$} \\
\hline & $\begin{array}{l}15-34 \\
(n=58)\end{array}$ & $\begin{array}{l}35-54 \\
(n=58)\end{array}$ & $\begin{array}{l}55-74 \\
(n=110)\end{array}$ & $\begin{array}{l}75+ \\
(n=70)\end{array}$ & \\
\hline Fall: from a height & 5.2 & 19.0 & 41.8 & 34.3 & 28.4 \\
\hline Fall: same level & 1.7 & 0.0 & 4.5 & 10.0 & 4.4 \\
\hline Hit by falling object & 12.1 & 15.5 & 13.6 & 7.1 & 12.2 \\
\hline Bitten/hit by animal & 1.7 & 6.9 & 4.5 & 0.0 & 3.4 \\
\hline Hit by moving object & 8.6 & 3.4 & 7.3 & 5.7 & 6.4 \\
\hline Contact heat or cold & 15.5 & 3.4 & 5.5 & 27.1 & 12.2 \\
\hline Contact electricity & 44.8 & 31.0 & 7.3 & 7.1 & 19.3 \\
\hline Rollover & 5.2 & 12.1 & 5.5 & 1.4 & 5.7 \\
\hline Other & 5.2 & 8.6 & 10.0 & 7.1 & 8.1 \\
\hline Total & 100.0 & 100.0 & 100.0 & 100.0 & 100.0 \\
\hline
\end{tabular}

absolute rates were highest in the oldest age group for all mechanisms (table 4).

There were just over 100 different agencies (mainly products or substances) involved at least once in the fatal incidents (up to three agencies were recorded for each incident). Common specific agencies were ladders (18\%), roofs (7\%), manual lifting equipment (mainly car jacks, 7\%), tractors $(5 \%)$, and portable electric cables $(5 \%)$.

The most common pathophysiological cause of death was head injuries $(23 \%)$. Other of the more common causes of death were electrocution (19\%), mechanical asphyxia (10\%), and multiple injuries, trunk injuries, and burns (each 6\%).

Information on blood alcohol levels was available for only $150(51 \%)$ of the home duties deaths. Raised blood alcohol levels (ranging from 0.051 to $0.254 \mathrm{~g} / 100 \mathrm{ml}$ ) appeared to have contributed to at least 15 home duties deaths-9.3\% of home duties deaths for which blood alcohol levels were available. Drugs did not seem to play a part in any of the home duties deaths, although information on drug levels was only available for $68(23 \%)$ of the deceased persons.

There were a number of similar scenarios that repeatedly resulted in death. These included the following situations:

- Persons (usually male) performing maintenance on cars which were inadequately supported and/or chocked, and which rolled or fell onto the deceased persons causing death through crush asphyxia or head injuries while they were under the car. Usually these persons were working alone and so there was no-one nearby to assist in lifting the car quickly enough to possibly save the person.

- Persons (usually male) on ladders that were not adequately braced, who suffered a fatal injury (usually to the head) when the ladder slipped or the person lost their balance, causing them to fall. This was a common occurrence in elderly persons.

- Persons killed in fires started as a result of them leaving the stove turned on after cooking or leaving something cooking while they fell asleep.

- Persons (usually male) performing maintenance on the home with faulty equipment or without ensuring the relevant electrical circuits had been isolated. As a result, the deceased received a fatal electric shock.

\section{DISCUSSION}

Fatal injuries involving home duties were found to occur at a rate of about 5.5 per million persons per year. This is one tenth of the rate of work related injury death of workers for the same period ( 5.5 deaths per 100000 workers per year). There is no appropriate comparison to the time based rate of 17.7 deaths per million persons per year per hour of home duties activity, because there are no time based rates available for work related fatal injury for workers

Males predominated, both in terms of absolute numbers and gender specific rates. This probably reflects the activities undertaken by men and women in the home. Population based rates were much higher in men for all activities except housework, but these rates do not take into account the amount of time spent on these activities. That is, they do not take into account exposure to specific hazards. Rates based on exposure showed that, compared with women, men had four times the risk of being fatally injured while undertaking housework, four times the risk while gardening, and 10 times the risk while involved in maintenance. This suggests that men are undertaking higher risk specific tasks than women when involved in these broad activities. For example, men may be more likely than women to climb a ladder when gardening. An alternative explanation for these results is that men undertake similar specific tasks as women but are more likely to be injured performing that task. This could arise, for example, if men are more "careless", or from physiological differences in susceptibility to injury between males and females. There was no evidence available to allow these possibilities to be rigorously assessed, but men undertaking higher risk specific tasks seems the most likely explanation for the study findings.

Rates increased particularly from age 55 years onwards, especially for women. The higher rates of fatal injury in older persons probably reflect several factors operating at the same time, including increased susceptibility to injury and decreased recuperative powers. Interestingly, the finding of an age related increase in risk is similar to that found for work related deaths of workers. ${ }^{9}$

The high proportion of incidents involving falls from ladders and involving electricity is not surprising, given the frequent exposure to these hazards and the significant risk they pose. The number of incidents related to car maintenance is less expected, although there are clearly significant risks involved, especially if cars are not appropriately supported when people are working under or around them. There were no exposure data available specifically for car maintenance activity, as it was included in the home maintenance activity group. However, it is likely that much more time is spent on general home maintenance than on car maintenance, and therefore that car maintenance is even a higher risk activity than suggested by the calculated rates. The first two of these activities have strong parallels with paid working activity, where electrocutions and falls (many from ladders) make up a sizeable minority of work related traumatic deaths. ${ }^{9}$ Therefore, prevention approaches used in the workplace to 
improve safety in these and other areas may well have components that could be transferred appropriately to the domestic setting.

There are few comparable studies of fatal or non-fatal injuries occurring in the circumstances of interest to this analysis. Most studies address all injuries occurring in the home (all, or nearly all, of which were non-fatal) or concentrate on home injuries in the elderly, especially those due to falls. However some of these studies provide relevant results. As in this study, the predominance of males, higher rates in males, and increasing rates with age have usually been reported. Falls were usually the predominant incident mechanism, as in this study. However, these falls were commonly less than one metre, whereas the falls in this study were generally from a greater height. Electricity rarely featured in the incidents in other studies, in contrast to this study's findings. Fire was also less common in other studies. As expected, injuries identified in other studies tended to be more minor, involving lacerations or sprain/strains, and to predominantly involve the upper or lower limbs. The differences between these findings and those of the current study are all consistent with the other studies covering entirely, or predominantly, non-fatal injuries, and these other studies including all injury circumstances rather than just those involving home duties as defined for this study. ${ }^{2-8}$

The comprehensive data collection used in this study makes it likely that the enumeration of home duties deaths was complete or virtually so. The available denominator data were collected in 1992, and so should be appropriate for the current analysis, which covered deaths occurring from 1989-92. The availability of information on time spent in various activities allowed activity specific rates to be calculated using appropriate denominator data summarising the period at risk. The lack of availability of time based data on specific activities means that comparison of time based rates within a broad category (for example, between home repairs and car care within the "home maintenance" category) may be biased. This is because the higher number of deaths during home repairs may arise because a lot more time is spent doing this than doing car care. However, the resultant rates are no less informative than the population based rates, and there is no such potential bias when comparing major categories. Further detail regarding task specific exposure would have allowed a more in-depth relative assessment of specific risks, but such data were not available. The relatively small number of deaths of women made assessment of their risks difficult for all activities except housework. Similarly, low numbers made assessment of risks for some age-sex activity combinations too imprecise to be useful.

\section{CONCLUSIONS}

Fatal injury of persons engaged in unpaid domestic work activities (home duties) was a significant cause of injury death ( $2 \%$ of all unintentional injury deaths) in Australia in the four year period 1989-92 inclusive. Use of activity specific denominator data allowed a more appropriate assessment of the degree of risk associated with each activity than has been available to date. The recurrence of similar circumstances surrounding many independent fatal incidents indicates areas

\section{Key points}

- Some home duties activities carry a high risk of fatal injury.

- Home repairs and car care are the highest risk activities.

- Use of activity specific denominator data provide the best assessment of risk.

- Ladders, electricity, and car supports are the main hazards.

- Preventative interventions can be targeted using this information.

where preventative interventions might be usefully targeted. The securing of ladders, awareness of electrical safety, and appropriate support of cars being worked on could all usefully be the subject of prevention programs.

\section{ACKNOWLEDGEMENTS AND DISCLAIMER}

The authors wish to thank the many individuals and government agencies who provided assistance in the design, planning and conduct of the overall study. They also wish to thank Ms Eui-Soo Choi and Ms Amelia Howland, who contributed to aspects of the design, conduct, and analysis of the overall study.

The planning, data collection, coding, and analysis of the overall study were conducted when the authors were employees of the National Occupational Health and Safety Commission. The views in this publication are those of the authors and do not necessarily reflect those of the commission.

\section{Authors' affiliations}

T R Driscoll, Centre for Occupational and Environmental Health, School of Public Health and Community Medicine, University of Sydney R J Mitchell, Injury Prevention and Policy Branch, NSW Department of Health

A L Hendrie, Health Communication Network

S H Healey, LIPID Coordinating Centre, University of Sydney

J A Mandryk, National Prescribing Service

B P Hull, National Immunisation Centre

\section{REFERENCES}

1 Watson W, Ozanne-Smith J. Injury surveillance in Victoria, Australia: developing comprehensive injury incidence estimates. Accid Anal Prev 2000;32:277-86

2 Carter S, Campbell E, Sanson-Fisher R, et al. Accidents in older people living at home: a community-based study assessing prevalence, type, location and injuries. Aust N ZJ Public Health 2000;24:633-6.

3 Hockey R, Miles E. Injuries in the home-adults. Injury Bulletin 2001;65(April): 1-4

4 Kopiar B, Wickizer T. Population-based study of unintentional injuries in the home. Am J Epidemiol 1996;144:456-62.

5 Kopiar B, Wickizer T. Home injuries among adults in Stavanger, Norway. Am J Public Health 1996:86:400-4.

6 Lindqvist K, Schelp L, Timpka T. Home injuries in a Swedish municipality-consequence and costs. Safety Science 1999;31:19-29.

7 Routley V, Valuri J. Home injuries. Hazard 1993;14:1-20.

8 Routley V', Ashby K. Safe home design. Hazard 1997;32:1-16.

9 Driscoll T, Mitchell R, Mandryk J, et al. Work-related fatalities in Australia, 1989 to 1992: an overview. Journal of Occupational Health and Safety-Australia and New Zealand 2001:17:45-66.

10 Australian Bureau of Statistics. Unpaid work and the Australian economy. Canberra: ABS, 1994.

11 Australian Bureau of Statistics. Australian demographic statistics. Canberra: ABS, 1993

12 Australian Bureau of Statistics. How Australians use their time-revised publication. Canberra: ABS, 1994

13 Bittman M. Recent changes in unpaid work-occasional paper. Canberra: Australian Bureau of Statistics, 1995. 